\title{
LOPE DE AGUIRRE: \\ LA CONSTRUCCIÓN DE UNA IMAGEN DEL PODER ${ }^{1}$
}

Lope de Aguirre: Constructing an image of power

Álvaro Baraibar*

Resumen

El presente trabajo analiza la manera en que el bachiller Francisco Vázquez, uno de los marañones que participó en la jornada, construyó la imagen del poder de Lope de Aguirre en su Relación de todo lo que sucedió en la jornada de Amagua y Dorado. La figura de Lope de Aguirre resulta especialmente sugerente a la hora de acercarse a aspectos relacionados con los conceptos de autoridad y poder en la América de la segunda mitad del siglo XVI.

Palabras clave: Crónicas de Indias, Lope de Aguirre, autoridad, poder.

Abstract

The figure of Lope de Aguirre proves to be particularly suggestive when considering the aspects related to concepts of authority and power in America during the second half of the $16^{\text {th }}$ century. With the present work, we pretend to analyze the way of constructing the image of power in Relación de todo lo que sucedió en la jornada de Amaga y Dorado of Lope de Aguirre, one of the marañones that took part in the journey. This text is a principle source of what occurred in the expedition. The characterization of the personalities illustrates the ideas concerning authority and power that the author and the protagonists of the journey had in mind.

Key words: Chronicles of the Indies, Lope de Aguirre, authority, power.

\section{INTRODUCCIÓN. EL CONTEXTO HISTÓRICO}

La rebelión de Lope de Aguirre en la jornada de Omagua y Dorado es, tal vez, uno de los episodios más conocidos de la tumultuosa historia de la conquista del Perú. En 1560 una expedición salía de tierras peruanas con el ánimo de descubrir las riquezas de una región llamada Omagua, situada en el cauce del río Marañón, actual Amazonas. ${ }^{2}$ Andrés Hurtado de Mendoza, marqués de Cañete y

\footnotetext{
${ }^{1}$ Este trabajo se enmarca en el proyecto "Red Europea: Autoridad y poder en el Siglo de Oro" del Programa Jerónimo de Ayanz del Plan de Formación de I+D 2009-2010 del Gobierno de Navarra (España).

${ }^{2}$ La fuente de estas noticias fueron unos indios llamados brasiles que habían llegado al Perú y que "contaron grandes cosas del río y de las provincias a él comarcanas, y especialmente de la provincia de Amagua, ansí de la muchedumbre de naturales y riqueza que en ella había, por lo cual pusieron deseo a muchas personas de las ir a ver y descubrir" (Vázquez, fol. 1v). Con todo, al margen de las noticias dadas por estos indios brasiles, el mito de El Dorado ya había cobrado fuerza desde unas décadas antes. Sobre el mito de El Dorado y sus formas a lo largo del siglo XVI ver Gil (1989). En el presente trabajo citaré la Relación de Vázquez por el manuscrito conservado en la Biblioteca Nacional de Madrid con la signatura Ms. 3199. Aunque son varias las ediciones
} 


\section{Álvaro Baraibar}

virrey del Perú, puso al frente de la expedición al navarro Pedro de Orsúa (o Ursúa), dándole el título de gobernador de aquella región.

La jornada hay que analizarla dentro del convulso siglo XVI peruano. En ella participan soldados que "que eran y habían sido traidores y se habían hallado en Pirú en muchos motines contra el servicio de su majestad" (Vázquez, fol. 21v). ${ }^{3}$ La expedición se convirtió en una sucesión de muertes y de rebeliones que fue narrada por varios de los testigos y por otros autores que, a pesar de no haber estado presentes, tuvieron acceso a los protagonistas y a sus testimonios (Jos, 1927:20-22; García Valdés, 1992:177-80). De todos estos textos la Relación de todo lo que sucedió en la jornada de Amagua y Dorado de Francisco Vázquez es una fuente fundamental, ya que en ella se basarían otros relatos tanto en el siglo XVI, como en el XVII (Díez Torres, 2011:63ss.; Lohmann Villena, 1990:LXIXss.). El bachiller Francisco Vázquez fue uno de los soldados marañones que escapó de Aguirre y escribió una relación de lo ocurrido como forma de poner en evidencia su lealtad al rey y su inocencia y para mostrar la terrible maldad del "cruel tirano Lope de Aguirre".

La rebelión de Aguirre y todo lo acontecido durante dicha jornada constituyen un escenario privilegiado para preguntarse sobre conceptos como los de autoridad y poder en la América de finales del siglo XVI. La Relación de Vázquez aporta mucha información acerca de estas cuestiones a la hora de explicar las razones de lo acontecido, así como al caracterizar los personajes de su historia. ${ }^{4}$ Por lo mismo, pretendo mostrar de qué manera Francisco Vázquez construyó en su Relación la imagen del poder de Lope de Aguirre y ver hasta qué punto podemos acercarnos a los argumentos empleados en la elaboración de esa imagen no sólo por parte del autor, sino también del protagonista, el propio Aguirre.

La Relación de Francisco Vázquez busca intencionadamente un importante valor pedagógico y ejemplarizante. Tras relatar los planes de los rebeldes y mostrar cómo pensaban tiranizar el Perú, Vázquez explica cuáles son las consecuencias de semejantes actos. El error de los tiranos había sido, en su opinión, no haber

existentes, como he explicado en otro lugar (Baraibar, "La jornada de Amagua (Omagua) y Dorado") sólo dos siguen a Vázquez, ya que el resto se basa en la versión de Almesto, y de ellas una (Ed. Ortiz de la Tabla para Alianza Editorial, 1987) lo hace a partir de una copia hecha por Juan Bautista Muñoz en el siglo XVIII y la otra (Ed. M. Cuesta para Turner, 1993) es un libro regalo que no es fácil localizar. Todo ello queda explicado también más en detalle en la edición de las relaciones de Francisco Vázquez y Pedrarias de Almesto que estoy preparando.

${ }^{3}$ En palabras de Lucas Fernández de Piedrahita (1688), siguiendo a su vez a fray Pedro Simón, dos de los primeros historiadores del Nuevo Reino de Granada, "uno de los principales motivos que tuvo el virrey del Perú para encargar la conquista de los omeguas al capitán Pedro de Ursúa, fue sangrar el cuerpo de aquel grande imperio de la sangre corrompida de muchos hombres baldíos, que entre las venas de sus provincias habían quedado como reliquias de los malos humores de Gonzalo Pizarro, Francisco Hernández Girón y don Fernando de Castilla" $(2,848)$.

${ }^{4}$ No me ocuparé, en este caso, de las cartas de Lope de Aguirre, que ya han sido objeto de estudio, entre otros, de Díez Torres tanto en su edición de El Marañón, de Diego de Aguilar, como en un trabajo que se puede consultar en ese mismo volumen. 
reparado en el gran poder de Dios, "que aunque por algún tiempo permita y sufra los semejantes crueles y tiranos para castigo de los pecados de los hombres, al fin los castiga y da el pago que sus crueldades y malas obras merecen”. Además, los tiranos tampoco habían tenido en cuenta la autoridad del rey — personificada en sus legítimos representantes en aquellas tierras - pues el monarca "por el nombre ha de ser acatado y reverenciado de los buenos y temido de los malos" (Vázquez fols. 36v-37r). En consecuencia, todas las acciones de los hombres quedan explicadas a la luz de la divina providencia, de modo que nadie puede escapar al castigo de Dios. La jornada de Omagua y Dorado y la propia figura y muerte de Lope de Aguirre son, en este sentido, un buen ejemplo de ello. ${ }^{5}$

\section{PEDRO DE ORSÚA Y FERNANDO DE GUZMÁN COMO FIGURAS DE AUTORIDAD}

En este marco general, es interesante fijar la mirada en la forma en que Vázquez retrata a los protagonistas $\mathrm{y}$, en la manera en que estos representan con sus personas y acciones las ideas de autoridad y poder en el siglo XVI. Tres fueron las figuras que dirigieron la jornada (Pedro de Orsúa, Fernando de Guzmán y Lope de Aguirre) y en ellas podemos ver un proceso de degradación de los valores que cada uno representa conforme se van alejando de la legítima autoridad emanada del monarca y, en última instancia, de Dios. ${ }^{6}$ En distintos momentos de la Relación, tras la muerte de cada una de estas tres personas, Vázquez nos ofrece un retrato de sus personalidades y de cuáles eran sus virtudes y defectos. Sus caracteres son un reflejo de sus acciones y viceversa, de modo que todo queda cerrado en sí mismo y perfectamente explicado. Pedro de Orsúa era un hombre de

cara alegre y hermoso, la barba taheña y bien puesta y poblada y era gentil hombre, de buena prática y conversación; mostrábase muy afable y compañero de sus soldados. Preciábase andar muy polido y ansí lo era en todas sus cosas. Parecía que tenía gracia especial en su palabra porque a todos los más que comunicaba los atraía a su querer y voluntad; trataba a sus soldados bien y mucha crianza. Fue más misericordioso que riguroso en castigar sus excesos. Sirvió siempre a su majestad bien y fielmente, sin que en él se hallase cosa en contrario, ni aun en el pensamiento, según lo que dél se entendía (Vázquez, 27v).

\footnotetext{
${ }^{5}$ Es interesante, como reflejo del pensamiento de la época, ver cómo Vázquez encuentra una explicación a la muerte y destrucción provocada por Aguirre en la isla Margarita en un episodio ocurrido unos días antes de la llegada del tirano, en el que el gobernador y el resto de autoridades de la isla sacaron de la iglesia a un soldado que se había acogido a sagrado arrastrándolo abrazado a la caja del Santísimo Sacramento, que terminó rodando por el suelo. "He querido decir esto — concluye Vázquez - para que se entienda la mucha reverencia que debemos tener a Nuestro Creador y Redemptor y a sus templos de oración y a sus ministros, y los que gobiernan y mandan repúblicas cómo deben mirar estas cosas con mucho cuidado y cristiandad porque, haciendo esto, todas sus cosas irán bien encaminadas" (74v-76r, cita en $75 \mathrm{v})$.

${ }^{6}$ Sobre la caracterización que Vázquez hace de estos tres personajes como retratos retóricos ver Calbarro (2004).
} 


\section{Álvaro Baraibar}

Vázquez, a la hora de caracterizar los personajes, nos muestra a un Orsúa con todas las condiciones necesarias para ser un buen gobernante, tal y como Bernardo de Vargas Machuca plasmaría en su Milicia y descripción de las Indias pocos años después, en 1599. Así, cuando casi al inicio de la jornada, cuatro soldados matan al capitán Pedro Ramiro, Orsúa los apresa y los lleva "al pueblo de Santa Cruz, adonde, guardándoles todos sus términos, los sentenció a muerte, forzando harto su voluntad por guardar justicia, y sin les admitir apelación les cortó las cabezas" (6v). El gobernador, en opinión de Vázquez, había actuado correctamente al permitirles que se defendieran y al ejecutarlos tras ser hallados culpables. ${ }^{7}$ El cronista utiliza su relato para exculpar a algunos y para mostrarlos como modelos de autoridad.

A pesar del retrato positivo y de valorar las dotes de buen caudillo de Orsúa, Vázquez considera que el gobernador había cometido dos errores a consecuencia de los cuales habría de llegar su "total destruición" (7v). Antes de que Orsúa partiera de la provincia de los motilones, un buen amigo suyo, Pedro de Añasco, le aconsejó que dejara fuera de la expedición tanto a su amante (doña Inés), como a algunos soldados "bulliciosos y desahogados" (26r). "Si entrambas o cualquier dellas el gobernador hiciera, oso afirmar que nunca sucediera lo que atrás se ha dicho" $(26 \mathrm{v}){ }^{8}$

En efecto, para el cronista la mala influencia de doña Inés, que "le tenía enhechizado", había convertido a Orsúa en alguien codicioso, ingrato, rencoroso, desabrido y "descuidado en la buena gobernación y disciplina de su campo y armada" (28). El embrujo de doña Inés era el que había hecho de un guerrero victorioso, experimentado, afable y bien querido por sus soldados, algo diametralmente opuesto. ${ }^{9}$ Vázquez relata cómo Orsúa, cuando descubre que unos soldados se quieren amotinar para volverse al Perú, en lugar de castigarlos "conforme era razón" les hizo remar "en el barco donde iba su amiga, que fuera mejor colgarlos de un palo, porque tomaron aquello por afrenta" $(21 \mathrm{r}) .^{10}$

\footnotetext{
${ }^{7}$ Ver, en este mismo sentido, lo relatado por Vargas Machuca (2003:105) para otro caso similar que se cita como ejemplo del buen hacer de un capitán.

${ }^{8}$ Vargas Machuca, al explicar cómo debe ser buen cristiano el caudillo, indica expresamente que "no ha de estar amancebado" (68) y poco después al referirse al modo de hacer soldados y las prevenciones que conviene tener dice: "huirá de soldados inquietos, porque más le importará entrar en su jornada con diez menos que llevar en su campo quien se lo revuelva y amotine" (88).

9 Según nos informa Vargas Machuca el caudillo "ha de ser ejemplo de todos sus soldados huyendo de conversaciones deshonestas y ociosas, que es una cosa que descompone mucho la autoridad y respeto, porque no hay cosa por donde el soldado más presto lo pierda, y así debe apartarse de serlo, mayormente en estar amancebado, porque, después de ser dañoso para el alma, anda en mucho peligro el cuerpo y todo en lo que pusiere mano se lo deshará, porque quien anda en pecado mortal, es cierto tendrá malos sucesos y el soldado le perderá el respeto que le debe, conque en toda cosa tendrá mal fin" (83-84).

10 Aunque la imagen de Orsúa es positiva, Vázquez cuestiona alguna de las decisiones del gobernador. Por ejemplo, cuando "por sola su autoridad" nombra a Alonso Henao vicario de la 
Sin embargo, a pesar de todo ello, Orsúa era el legítimo representante del rey, tal como se encargó de recalcar el propio Lope de Aguirre, aunque con un objetivo totalmente diferente. El navarro era un gobernador del rey que "llevaba sus poderes y representaba su persona" (Vázquez, 30v). Siendo así, la ofensa cometida con su muerte no se hizo sólo a la persona de Orsúa, sino al mismísimo monarca. El cronista entiende que, aunque sus errores y pecados pudieran explicar el porqué de su muerte, nunca podían haber dado al hecho legitimidad alguna. Por ello, quienes se alzaron contra Orsúa lo hicieron también contra el rey y pasaron a recibir inmediatamente, por parte de Vázquez, el calificativo de tiranos. ${ }^{11}$

Pedro de Orsúa era una figura de autoridad, aunque esta se viera cuestionada por su mal gobierno. Su autoridad se derivaba de su condición de caballero y, fundamentalmente, del hecho de ser el representante del rey. Tras la muerte del navarro, es significativo comprobar cómo las decisiones de los rebeldes se siguen rigiendo por los mismos principios contra los que, en teoría, se habían alzado. Quienes habían participado en la muerte de Orsúa, nos dice el cronista, "eran gente baja y de poca suerte, y los más oficiales de oficios bajos". De este modo, "no teniéndose ninguno por suficiente para ser capitán y cabeza, a quien la gente obedeciese de buena gana, se concertaron con el don Hernando de Guzmán, que era alférez del campo, que allende de ser caballero era tenido por virtuoso y bien quisto entre ellos" (22r). ${ }^{12}$

El segundo personaje que pasa a dirigir la jornada es Fernando de Guzmán, quien representa dos pasos en ese proceso de degradación de los dirigentes de la jornada. El primero - que implica traición - al dejarse convencer para ocupar el cargo de general una vez fuera desposeído de él Pedro de Orsúa. El segundo y más grave — que supone, además, alta traición— al aceptar el plan de convertirse en príncipe del Perú, desnaturalizándose de los reinos de España y negando el vasallaje a Felipe II (Vázquez, 38vss.).

Guzmán era, en palabras de Francisco Vázquez, "gentil hombre, de ánimo reposado y aun descuidado; era virtuoso, enemigo de toda crueldad". Pero "fuera desto era vicioso, glotón, amigo de comer y beber". Fue ingrato con su gobernador, que siempre lo había honrado, que lo había nombrado su alférez general, el cargo más importante de su campo, y al que mató por ambición. "Durole el mando en la tiranía con nombre de general y después de príncipe, casi cinco meses, que en ello no tuvo tiempo de hartarse de buñuelos y otras cosas en que ponía su felicidad"

\footnotetext{
jornada (19v). Orsúa es también quien roba y secuestra a un fraile que, después de haberle prometido 2.000 pesos, se arrepiente de ello y no quiere dárselos $(3 \mathrm{v}-4 \mathrm{v})$.

${ }^{11}$ Vargas Machuca es contundente al explicar cómo el soldado "está obligado a no consentir motín" porque, "además de deservir a Dios desirve al rey y es especie de traición y en ello aventura su honra y vida" (2003:104).

${ }^{12}$ Vargas Machuca hizo notar lo mucho que importaba al caudillo "tener nobleza" y "más en la milicia indiana que en otra alguna" a causa de la "presunción que en aquella milicia tienen los soldados de que se les puede fiar y encargar a cada uno el gobierno de las Indias" (269).
} 


\section{Álvaro Baraibar}

(46). Guzmán aparece retratado, pues, como alguien alejado de las virtudes del buen caudillo y más preocupado por disfrutar de los placeres de la vida.

Guzmán, además, carece de legitimidad para ocupar el cargo de general del campo porque es en realidad un tirano, alguien que ha ejercido una violencia ilegítima para conseguir sus objetivos. La autoridad de Guzmán se basa en su condición de noble y en la estimación que los miembros de la expedición pudieran tener por él. A pesar de ello, Guzmán escenificó su autoridad como lo haría un príncipe legítimo, como si fuera el "rey don Felipe nuestro señor, y con tanta reverencia y acatamiento", nos cuenta Vázquez:

le llamaron excelencia y él abrazaba a todos y no daba a nadie la mano. Mostró placer y holgose con el nuevo nombre y ditado, luego puso casa de príncipe con muchos oficiales y gentiles-hombres que le sirvían y acompañaban; comió desde entonces solo y servíase con ceremonias; cobró alguna gravedad con el nuevo nombre; dio nuevas condutas a sus capitanes señalándoles salario de a diez y veinte mil pesos en su caja y haciendas; y sus cartas empezaban: "Don Fernando de Guzmán, por la gracia de Dios, príncipe de Tierra Firme y Pirú" (35r).

Cuando Fernando de Guzmán es asesinado por Aguirre "a estocadas y arcabuzazos", Vázquez es rotundo: "así feneció la locura y vanidad de su principado y pereció allí la gravedad que había tomado y todas sus cuentas salieron vanas" (46r). En definitiva, Guzmán carecía de toda legitimidad para representar al rey.

\section{LOPE DE AGUIRRE: LA IMAGEN DEL PODER}

Finalmente, la dirección de la jornada la asume Lope de Aguirre, en quien estuvo el poder desde el primer momento, siendo caracterizado a lo largo de los textos en muchas ocasiones con rasgos demoníacos. Vázquez nos habla de un hombre "pequeño de cuerpo y de poca persona, mal agestado, la cara chupada y algo pequeña, los ojos que, si miraba de hito, le estaban bullendo en el casco, especial cuando estaba enojado". Vázquez no le concede ni una sola virtud, aunque reconoce que "era de agudo y vivo ingenio para ser hombre sin letras". En palabras del cronista, Aguirre era "enemigo de los buenos" y virtuosos y "amigo y compañero de la gente baja e infames hombres"; era "cauteloso, vario y fementido, engañador, de poca verdad, pocas veces guardaba palabra que daba"; era "vicioso, lujurioso, glotón, tomábase del vino"; y era "mal cristiano y aun hereje luterano o peor, pues mataba clérigos y frailes, mujeres, niños inocentes y aunque los que mataba pedían confesión no la consentía dar aunque hubiese aparejo" (113v-114r). En Perú se lo conocía como "Aguirre el loco" (115r). Era, en definitiva, la personificación del traidor: "quedará memoria entre los hombres la que quedó del malvado Judas, para blasfemar y escupir del más perverso hombre que ha nacido en el mundo", afirma Vázquez (111v). 
Lope de Aguirre desde el primer momento había detentado el poder. En la Relación, Aguirre va dirigiendo las acciones de los rebeldes en una suerte de huida hacia adelante sin posibilidad alguna de perdón o de salvación por parte del monarca. La crónica muestra, en realidad, la historia de la rebelión de Lope de Aguirre contra la autoridad establecida y la escenificación de su poder, ilegítimo, violento, pero real.

Si bien el plan inicial de Guzmán y los rebeldes fue el de "alzarse con los navíos y canoas y salirse a la mar, y de allí irse al Pirú", Lope de Aguirre y Lorenzo de Salduendo decidieron y convencieron a los demás de que "mejor era matar al gobernador y alzarse con todo" (Vázquez, 22v). Muerto Orsúa, los tiranos pensaban seguir con los planes de la jornada y justificar la muerte del gobernador diciendo que "iba remiso y descuidado en buscar la tierra, y que no la pretendía poblar ni buscar, y otras mentiras y maldades", escribe Vázquez (30r). Todo ello quedó plasmado en una información que debía ser firmada por todos. En aquel momento, Aguirre llevó la rebelión a un punto de no retorno al firmar como "Lope de Aguirre traidor" y enfrentarse a Alonso de Montoya y Juan Alonso de la Bandera. Aguirre consideraba una "locura y necedad" el intento de justificar la muerte de un representante del rey.

Al poco tiempo, Aguirre mató a Juan Alonso de la Bandera con la participación de Guzmán y convenció a este para ser designado príncipe y desnaturalizarse de España. A partir de aquí, Aguirre acabó con la vida de todos aquellos que cuestionaron su posición o sus decisiones, hasta llegar a asesinar a Lorenzo de Salduendo en presencia de un Fernando de Guzmán que nada pudo hacer para evitarlo y que fue objeto de los insultos y amenazas de un "muy bravo y enojado" Lope de Aguirre. ${ }^{13}$ Poco después fue el propio Guzmán quien murió a manos del tirano, que asumió finalmente el mando de la jornada "rodeado de más de 80 de sus amigos bien armados", es decir, dando claras muestras de su poder y desacato a lo establecido (43r).

Vejaciones y humillaciones, insultos e injurias, burlas, desprecios e ironía, injusticia y crueldad, miedo y terror son elementos que configuran el personaje de Lope de Aguirre en la crónica de Francisco Vázquez. La lista de víctimas de Aguirre se elevó a "más de sesenta hombres, y entre ellos dos frailes y un clérigo y cuatro mujeres con su hija" (Vázquez, 113r), pero tan importante como el número o más es en este caso el cómo de algunas de dichas muertes. Es muy significativo ver cómo actúa Aguirre a la hora de construir la imagen de su poder. ${ }^{14}$

\footnotetext{
${ }^{13}$ Vázquez relata cómo Salduendo pide a Guzmán que lo defienda, pero "el traidor del tirano no le dio ese lugar, que delante de su príncipe lo mató a estocadas y lanzadas sin le tener respecto ni dársele nada dél aunque le rogaba y mandaba que no lo hiciese". Tras ello Aguirre "dijo a su príncipe muchas desvergüenzas, en que le dijo que no se había de fiar de ningún sevillano" y que "le valdría más gastar de los guijarros de Pariacaca que comer buñuelos que le daba Gonzalo Duarte, su mayordomo" (Vázquez, 43).

${ }^{14}$ Díez Torres, "Estudio preliminar" (2011:39-54), a partir sobre todo de las cartas de Lope de Aguirre, ha hecho un retrato de su "posición ideológica" (48).
} 
La crónica insiste en vejaciones y humillaciones por parte de Lope de Aguirre presentes de forma insistente en las páginas de la crónica. Así, dice que en la Margarita mandó a buscar a

un mancebo que estaba en la isla que no le había venido a ver y, en pena de su descuido, mandó que le rapasen la barba, lavándosela primero con orines hediondos, y le mandó que pagase al barbero y le hizo traer cuatro gallinas por paga. Y a otro soldado de sus marañones, llamado fulano Cayado, que no era hombre de quien él hacía cuenta ni le quería matar, porque se descuidó un día de venir al escuadrón le mandó ansimismo rapar la barba en el rollo de la plaza y que se la lavasen con el mismo lavatorio que al otro (73).

En Lope de Aguirre, el insulto se muestra variado a lo largo de la relación con la intención de degradar a quienes tuvieran autoridad: Pedro de Orsúa es un francés $;^{15}$ Fernando de Guzmán un sevillano, y como tal hombre del que uno no se podía fiar; ${ }^{16}$ y el licenciado Pablo Collado, gobernador de Venezuela, no era más que un "gobernadorcillo bachillerejo de dos nominativos" (Vázquez, 101v). El desprecio y la burla aparecen en muchos casos, despojando a sus víctimas de la honra del soldado. Aguirre explica cómo a causa de que "su príncipe y los demás no se habían sabido gobernar habían muerto como mozos" (47r). Otros casos muy claros son los de soldados cuyo cadáver aparece con un rótulo (Díez Torres, 2011:49-50), como por ejemplo "un Monteverde flamenco", al que decidió matar por andar tibio en la guerra y que "amaneció un día muerto y puesto un rétulo en el pecho que decía: "por amotinadorcillo"' (49v); o el de un soldado llamado Pérez al que ahorcó por estar enfermo y al que también puso "un título en los pechos que decía: "por inútil y desaprovechado"” $(87 \mathrm{v})$.

Aguirre, por otro lado, mata sin dejar que sus víctimas tengan la ocasión de defender su causa, a diferencia de lo que haría un buen gobernante, ejemplificado en Pedro de Orsúa (Vázquez 6v, ya citado). Pero, además y sobre todo, lo hace sin

\footnotetext{
15 "En el año de cincuenta y nueve dio el marqués de Cañete la jornada del río de las Amazonas, que por otra parte llaman Omagua, a Pedro de Orsúa, navarro, y por decir verdad francés” (Vázquez, 84). La referencia a Orsúa como francés tiene toda la carga negativa del enemigo de Castilla, aliado con los príncipes protestantes contra los intereses españoles en la lucha por la hegemonía en Europa. Los últimos reyes de Navarra, así como sus descendientes, no sólo eran vasallos del rey de Francia, sino también sus parientes: Enrique II, hijo de Catalina de Foix y Juan de Albret, se casó en 1527 con Margarita de Angulema, hermana del rey Francisco I de Francia. Su hija, Juana III de Navarra, se convirtió al protestantismo en 1560 y su nieto se convertiría en Enrique IV de Francia. Por otro lado, cuando Enrique II trata de recuperar Navarra en 1521 lo hizo con la ayuda de Francisco I de Francia. La vinculación de la casa real navarra con la francesa fue uno de los argumentos a la hora de justificar la conquista por parte de Castilla. Sobre la imagen que los españoles tenían de los franceses en el siglo XVII. Cfr., Herrero-García (1928:405ss.).

16 "Muerto Lorenzo de Salduendo, el tirano dijo a su príncipe muchas desvergüenzas, en que le dijo que no se había de fiar de ningún sevillano" (Vázquez, 43r). Al respecto de la imagen que se tenía ya en el siglo XVII de los andaluces en general y de los sevillanos en particular, así como de la mala fama de los soldados que procedían de aquellas tierras. Cfr., Herrero-García (1928:169ss.).
} 
concederles la posibilidad de confesar sus pecados antes de morir. Este elemento resulta clave en la mentalidad de la época a la hora de caracterizar el grado extremo de injusticia del tirano. Partidos del pueblo de la Jarcia, Aguirre mandó a Antón Llamoso a matar al comendador Juan de Guevara. Tras darle tres puñaladas "le echó al río donde murió ahogado pidiendo a voces confesión, y el tirano lo miraba con mucho placer" (50v). De igual modo, poco después, al llegar a la isla Margarita "mandó dar garrote sin confesión" a Gonzalo Giral de Fuentes y a Diego de Balcázar $(55 \mathrm{v}) .{ }^{17}$

Desde un primer momento, el alzamiento de Lope de Aguirre es en sí mismo una afrenta al propio rey. De hecho, en su rechazo y desprecio de la autoridad real Aguirre va construyendo también la imagen de su poder, que podríamos considerar como un contrapoder. La muerte de Pedro de Orsúa, de Juan de Villandrando, gobernador de la Margarita, así como del alcalde y otros regidores de la isla son agravios cometidos contra la persona misma del rey, en cuanto que son sus representantes. Pero, además, Aguirre quiso ser más gráfico, si cabe, cuando al llegar a la Margarita rompió los objetos que podían simbolizar la presencia de la administración del rey en la isla: el rollo, en cuanto imagen de la justicia real, y la caja "de las tres llaves", en cuanto símbolo de la hacienda real. ${ }^{18}$

Las burlas de Aguirre se dirigen también a la imagen del rey y de la monarquía. Tal y como ha puesto de relieve Díez Torres (50), Aguirre se mofa en más de una ocasión del poder taumatúrgico atribuido a los monarcas. Si bien es verdad que en Castilla no existe todo el ritual que confiere a los reyes franceses virtudes taumatúrgicas, sí es cierto que de una manera indirecta se hace referencia a dicho poder, aspecto este que es recordado por varios cronistas bajomedievales y también por otros autores durante la Edad Moderna (Nieto Soria, 67; Asensio, 146-48). Así, Aguirre concluye la carta a Montesinos, provincial dominico, con una burla al poder taumatúrgico de los reyes: "tratémonos bien, y ande la guerra; porque a los traidores Dios les dará la pena y a los leales el rey los resucitará, aunque hasta agora no hemos visto que haya resucitado ninguno ni sana heridas ni da dádivas". ${ }^{19}$ Poco después, cuando llegados ya a la Valencia, tras decapitar y hacer pedazos a Diego de Alarcón —uno de los soldados que se había escapado y

\footnotetext{
${ }^{17}$ Hay otros casos, como Enríquez de Orellana, Luis Sánchez del Castillo y Juan de Villatoro (61r-62r).

${ }^{18}$ Lope de Aguirre "y otros muchos fueron con hachas a cortar el rollo de la plaza del pueblo y le dieron muchos hachazos, y como era de guayacán muy duro, no le acabaron de cortar, que se cansaron; y mientras lo cortaban decían muchas palabras contra nuestro rey y señor denostando su persona" (Vázquez, 59). Acto seguido hicieron pedazos la caja del rey, robaron lo que en ella había y rompieron los libros de las cuentas reales.

${ }^{19}$ Vázquez, 69r. Aguilar y Almesto recogen una frase similar, aunque traen "vidas" en lugar de "dádivas".
} 


\section{Álvaro Baraibar}

había sido apresado $-{ }^{20}$ pasando junto al rollo de la plaza vio su cabeza, Aguirre preguntó: “¿Cómo no viene el rey de Castilla a resucitaros?” (Vázquez, 92v).

Por otro lado, aunque hay ocasiones en que Aguirre parece pensar que no puede haber ni perdón ni salida para él y los suyos tras haber matado a Orsúa, en otros momentos nos da pistas de que pudo imaginar un proyecto político de futuro, bien fuese por convicción o por dar esperanza a sus marañones. Vázquez nos cuenta cómo, estando en la isla Margarita, "fue el dicho tirano con todos sus soldados en ordenanza a la iglesia mayor del pueblo a bendecir ciertas banderas de sus capitanes". Tras la bendición, entregó las banderas "a sus capitanes y alférez" y les dijo que "las pueden defender de todo el mundo y que no les encargaba ni mandaba más de que mirasen por la honra de los templos y de las mujeres, y que en lo demás viviesen como les pareciese y en la ley que quisiesen". La referencia de Vázquez concluye con unas palabras de Aguirre muy elocuentes: "dijo aquí a sus soldados, que él había hecho nuevo rey y que había de hacer nueva ley para en que viviesen sus secuaces y amigos" (70v-71r). ${ }^{21}$ Vázquez nos presenta, por tanto, a un Aguirre dispuesto a romper por completo con las normas establecidas designando nuevo rey y nuevas leyes en las que vivir. ${ }^{22}$

La imagen del poder que se construye en torno a la figura de Lope de Aguirre está muy asociada a la del hombre de armas. Lope de Aguirre ensalza la guerra como algo natural. ${ }^{23} \mathrm{En}$ su caso, la guerra es también una forma de vida y de promoción social, en el servicio a la monarquía en tierras americanas. "En mi mocedad - le dice a Felipe II- pasé el mar océano a las partes del Pirú por valer más con la lanza en la mano y por cumplir con la deuda que debo de hombre de bien" (Vázquez, 79v). Por ello mismo, en virtud de los valores soldadescos que representa, Aguirre desprecia a los "presidentes y oidores y obispos, arzobispos, gobernadores letrados y procuradores" porque "ellos y frailes tenían destruidas las Indias" $(62 \mathrm{v}){ }^{24}$

${ }^{20}$ Esta imagen de Alarcón ("le cortaron la cabeza y hecho cuartos los pusieron en palos por los caminos" Vázquez, 92v) se repetirá después en el caso del propio Lope de Aguirre cuando sea apresado y muerto en Barquisimeto.

${ }^{21}$ Díez Torres se ha referido a este pasaje de la bendición de las banderas en la isla Margarita como un ejemplo del intento de Aguirre de "fomentar un sentimiento de identidad colectiva en su hueste" ("Estudio preliminar", 2011:53).

${ }^{22}$ Sobre los antecedentes históricos de estas ideas en las rebeliones peruanas ver Díez Torres ("Estudio preliminar", 2011:42ss.).

${ }^{23}$ Cuando Aguirre llega al pueblo de Valencia y ve que está vacío porque los habitantes de la región huyen y no se pasan a su bando ni se enfrentan a él, dice "no creía en tal, si la gente de aquella tierra no eran peores que bárbaros y pusilánimos y cobardes" y que sólo ellos "rehusaban la guerra, que desde el principio del mundo los hombres la habían amado y seguido, y aun en el cielo la había habido entre los ángeles cuando echaron dél a Lucifer" (Vázquez, 91v).

${ }^{24}$ Caro Baroja se refirió al desprecio y aun odio de Aguirre hacia los hombres de letras y los frailes y al papel de la violencia y la fuerza en su pensamiento, poniéndolos en relación con tradiciones medievales e ideas existentes en las guerras banderizas de las tierras vascongadas (99-106). Sin embargo, parece que en Aguirre lo que subyace, en realidad, no es sino un claro rechazo a todo representante de la autoridad del monarca y del orden establecido. 


\section{Algunas ideAs de AguirRe mÁs ALLÁ DEL PERSONAJE}

En este mismo sentido, desde esta mirada del soldado de Indias, Lope de Aguirre trató de argumentar las razones de su rebelión y al hacerlo ofreció una interesante perspectiva al respecto de algunas de las ideas que aparecen en los debates sobre el derecho de resistencia y el tiranicidio a lo largo de los siglos XVI y XVII y que perduraron en la literatura del Siglo de Oro (Usunáriz, "Tiranicidio y derecho de resistencia"). Aguirre se queja en su carta a Felipe II del triste destino de los soldados, que tanto han dado por su rey en la conquista de las Indias y que tan poco han recibido a cambio y se dirige a Felipe II diciéndole: "no puedes llevar con título de rey justo ningún interés destas partes donde no aventuraste nada, sin que primero los que en ello han trabajado y sudado su sangre, sean gratificados" (Vázquez, 81r).

La queja manifestada por Lope de Aguirre era una reivindicación muy presente en las Indias Occidentales. Vargas Machuca también la recogió al ensalzar la labor del soldado en las Indias: "cada año, uno con otro, nos entra por la barra de Sanlúcar en nuestra España muchos millones de dinero, plata y oro; y esta riqueza resulta del trabajo de sus personas [los soldados] y del valor de sus espadas" (2003:66). A pesar de ello, los conquistadores y sus descendientes, dice Vargas Machuca

mueren en su pobreza, cosa bien lastimosa y digna de remedio, pues quien fue para ganar la tierra, también será para gobernarla tan bien como otros y aun mejor, por el mejor derecho, práctica y obligación que para ello tienen, sin les preferir gentes nuevas desnudas de todo mérito en aquellas partes (2003:66).

Y si bien puede ser cierto — continúa Vargas - que a algunos les falta el talento necesario para gobernar "no le faltara para comer la merced que su rey le hiciere por lo que él o sus pasados han servido. Que de no hacer esta consideración algunos gobernadores, han resultado grandes males" (66). ${ }^{25}$

Siendo así, no es de extrañar que los rebeldes creyeran que su causa era compartida por otros muchos. Por ello, muerto Orsúa y designado Guzmán como príncipe, el plan consistía en tomar por la fuerza lo que les correspondía o, en palabras de Francisco Vázquez, "tiranizar el Pirú". Pensaban "dar sobre el pueblo del Nombre de Dios y tomalle y roballe y abrasalle" (36r) y creían, además, que "se le había de juntar la gente de Veragua y otros muchos y españoles de Nicaragua y otras partes, y más de mil negros a quien ellos habían de dar armas y libertad" (36v).

Caro Baroja (1983:82ss.) y Blas Matamoro (1986:103-5 especialmente) sugieren raíces medievales en el razonamiento de Aguirre. Matamoro se ha referido a

${ }^{25}$ Vargas Machuca insistió en ello también en el libro 4, cap. 5, donde habla del "Premio de pobladores" (2003:154-56). 


\section{Álvaro Baraibar}

la idea de que Lope de Aguirre viera a Felipe II como un tirano injusto que no gratificaba convenientemente a sus vasallos, quedando estos "habilitados para reponer el pacto original por medio del tiranicidio" (110). En la línea de lo defendido por la Escuela Jurídica Española, el pacto original es el suscrito entre Dios y su pueblo, base de todo el orden legal (Bullón, 1936). De él se "deriva el legítimo ejercicio del cargo (gobernador o rey). Un ejercicio ilegítimo lo hace atacable, y tanto Dios como el pueblo pueden desligarse del compromiso de obedecer al príncipe, que se ha convertido en tirano, o sea en mandatario fuera de la ley" (1936:104). Como ha afirmado Usunáriz, si bien es cierto que "buena parte de las ideas 'pactistas', 'constitucionalistas' están vinculadas al pensamiento medieval", no sería "hasta el siglo XVI cuando la polémica se avivó", a causa, en primer lugar, del fortalecimiento del Estado moderno y el interés de algunos en poner límites a la autoridad del poder real y, en segundo lugar, el papel desempeñado por los monarcas en la lucha contra la herejía como consecuencia de la ruptura religiosa y el debate que se suscitó en torno al derecho de resistencia (1936:97).

Evidentemente, Lope de Aguirre trata de adaptar los argumentos a sus propios intereses. A pesar de que Aguirre pudiera considerar tirano a Felipe II por los agravios que aduce, el derecho de resistencia (y no digamos ya el tiranicidio) no podía ser ejercido "por la iniciativa privada de cualquier ciudadano, sino por resolución pública, es decir, por acuerdo expreso de calificadas y suficientes representaciones del país tiranizado" (Bullón, 1936:161, citado por Usunáriz, 2008:107). Un caso diferente es el del propio Aguirre, que no es sino un tirano $a b$ origine, es decir, por usurpación violenta: aquel "que sin ningún título ni derecho se ha adueñado violentamente de la autoridad suprema y la ejerce en daño gravísimo de la sociedad". En este caso, "no sólo se le puede y debe resistir, sino que cualquier ciudadano está facultado para darle la muerte, aunque no haya precedido juicio o proceso contra el usurpador, ni autorización o delegación expresa de la colectividad" (Bullón, 1936:153-54, cit., por Usunáriz, 2008:104). Así parece que lo entendió el propio Aguirre cuando afirmó que habiendo matado al gobernador Orsúa, aunque hallasen la tierra que buscaban, "el primer bachiller que a ella viniese les cortaría las cabezas a todos” (Vázquez, 30v).

\section{A MODO DE EPÍLOGO}

La convulsa realidad del virreinato del Perú en el siglo XVI, la imagen de América como un mundo autónomo de la metrópoli (idea que, por ejemplo, también aparece en los franciscanos de Nueva España), un cierto malestar muy presente en las Indias Occidentales que reivindica los derechos de quienes llevaban más tiempo en aquellas tierras frente a los que llegaban desde España para ocupar cargos sin mérito alguno en el desarrollo de la conquista. Son aspectos que, de una forma más o menos consciente, más o menos articulada, actúan como resortes en algunas de las ideas que hemos analizado del personaje de Lope de Aguirre construido por Francisco Vázquez. La actitud de Aguirre y 
las ideas que dan razón de sus acciones responden, evidentemente, a un tiempo histórico, pero también deben ser entendidas dentro de un contexto geográfico que aporta matices. Aguirre proyecta su forma de pensar desde su vivencia personal en tierras americanas y es precisamente su experiencia americana la que da sentido a algunas de sus ideas, la que las hace posibles precisamente en aquella realidad. La crónica de Vázquez nos muestra de qué forma Aguirre fue construyendo la imagen de su poder y cómo argumentó y justificó sus acciones. Es complejo en ocasiones tratar de discernir en qué medida la burla o la crítica de la realidad que hace Aguirre representa el intento de un nuevo proyecto político o, por el contrario, la voluntad de perpetuar una situación previa.

En este sentido, cabe preguntarse hasta qué punto Aguirre imaginó un nuevo horizonte de expectativas - desde el nuevo espacio de experiencia americano que se estaba construyendo a partir de la vida en un Nuevo Mundo (Baraibar, 2010) - o se limitó a reproducir el mismo contra el que se rebeló, pero ubicándose a sí mismo en una posición más favorable. Matamoro explicó cómo había sido el sentido del honor lo que había llevado a Aguirre a revolverse contra el orden establecido, pero como una forma, simplemente, de resolver la injusticia cometida con él mismo y con los conquistadores en general: "El honor es un concepto vinculado con el lugar que cada sujeto ocupa en la sociedad. Lope de Aguirre se insurge contra el rey, precisamente, por entender que su lugar en la sociedad no está correctamente reconocido por el gobernante" (1986:108).

Aunque resulte tentador pensar que Lope de Aguirre pudiera haber imaginado una organización política y social diferente (un nuevo rey y una nueva ley, en palabras de Aguirre rescatadas por Vázquez en su Relación), probablemente la explicación más plausible de lo ocurrido haya que buscarla precisamente en la reacción de un conquistador que se sentía olvidado, desfavorecido y minusvalorado $\mathrm{y}$, por tanto, ofendido en su honor de hidalgo por parte de la Corona, más preocupada por otras coordenadas políticas y geográficas y más proclive a conceder mercedes a otras gentes.

Universidad de Navarra*

Grupo de Investigación Siglo de Oro (GRISO)

Campus universitario $s / n$

31009 Pamplona-Navarra (España)

abaraibar@unav.es 


\section{Álvaro Baraibar}

\section{BIBLIOGRAFÍA}

Asensio, Eugenio. La España imaginada de Américo Castro. Barcelona: El Albir, 1976. Baraibar, Álvaro. "La jornada de Amagua (Omagua) y Dorado: entre Francisco Vázquez y Pedrarias de Almesto", en Taller de Letras, 2011.

"La naturaleza en el discurso indiano. La construcción de un espacio de experiencia americano". Ponencia presentada en el Congreso internacional "De la colonia a la independencia”. Barcelona, 27-29 de octubre de 2010.

Bullón Fernández, Eloy. El concepto de la soberanía en la Escuela jurídica española del siglo XVI. Madrid: Librería General de Victoriano Suárez, 1936.

Calbarro, Juan Luis. "Lope de Aguirre, el maldito. Retrato retórico", en Historia № 16342. 2004:30-39.

Caro Baroja, Julio. El señor inquisidor y otras vidas por oficio. Madrid: Alianza, 1983, $3^{\text {a }}$ (Ed).

Díez Torres, Julián. "Estudio preliminar" a su edición de Aguilar y Córdoba, D. de, en El Marañón. Madrid: Iberoamericana, 2011:11-123.

------- "Las ideas políticas de Lope de Aguirre, fuerte caudillo de la noble gente marañona", en Alpha No 33 (Diciembre 2011) (201-214).

Fernández de Piedrahita, Lucas. Historia general de las conquistas del Nuevo Reino de Granada. Bogotá: Imprenta de Medardo Rivas, 1881, 2 vols.

García Valdés, C. C. “Una visión original de la jornada del Dorado: ‘El Marañón’ de Diego de Aguilar y de Córdoba", en Las Indias (América) en la literatura del Siglo de Oro. Homenaje a Jesús Cañedo. Actas Congreso Internacional celebrado en Pamplona, 15-18 de enero de 1992. (Ed.). I. Arellano. Pamplona: Gobierno de Navarra, Departamento de Educación y Cultura, 1992:175-98.

Gil, Juan. Mitos y utopías del Descubrimiento. 3. El Dorado. Madrid: Alianza, 1989.

Herrero-García, Miguel. Ideas de los españoles del siglo XVII. Editorial Voluntad: Madrid, 1928.

Jos, E. La expedición de Ursúa al Dorado, la rebelión de Lope de Aguirre y el itinerario de los "marañones". Huesca: Campo, 1927.

Lohmann Villena, G. "Estudio preliminar" a la edición de Aguilar y Córdoba, D. de., en El Marañón. Madrid: Atlas, 1990. IX-LXXXIII.

Matamoro, Blas. Lope de Aguirre. La aventura de El Dorado. Madrid: Historia 16, 1986.

Nieto Soria, José Manuel. Los fundamentos ideológicos del poder real en Castilla (siglos XIII-XVI). Madrid: EUDEMA, 1988.

Usunáriz, Jesús María. "Tiranicidio y derecho de resistencia en la Europa de los siglos XVI y XVII”, en Terrorismo y magnicidio en la historia. (Ed.). M. Vázquez de Prada. Pamplona: EUNSA, 2008:93-134.

Vargas Machuca, B. Milicia y descripción de las Indias. Ed. M. Cuesta Domingo y F. López-Ríos Fernández. Valladolid: Instituto Interuniversitario de Estudios de Iberoamérica y Portugal, 2003.

Vázquez, Francisco. Relación de todo lo que sucedió en la jornada de Amagua y Dorado, que el gobernador don Pedro de Orsúa fue a descubrir, con poderes y comisiones que le dio el virrey marqués de Cañete, presidente de Perú. Trátase, asimismo, del alzamiento de don Hernando de Guzmán y Lope de Aguirre y otros tiranos, Biblioteca Nacional de Madrid, Ms. 3199. 